\title{
New information on scavenging and selective feeding behaviour of tyrannosaurs
}

\author{
David W.E. Hone and Mahito Watabe \\ Acta Palaeontologica Polonica 55 (4), 2010: 627-634 doi: http://dx.doi.org/10.4202/app.2009.0133
}

Feeding traces for carnivorous theropod dinosaurs are typically rare but can provide important evidence of prey choice and mode of feeding. Here we report a humerus of the hadrosaurine Saurolophus which was heavily damaged from feeding attributed to the giant tyrannosaurine Tarbosaurus. The bone shows multiple bites made in three distinctive styles termed "punctures", "drag marks" and "bite-and-drag marks". The distribution of these bites suggest that the animal was actively selecting which biting style to use based on which part of the bone was being engaged. The lack of damage to the rest of the otherwise complete and articulated hadrosaur strongly implies that this was a scavenging event, the first reported for a tyrannosaurid, and not feeding at a kill site.

Key words: Dinosauria, Theropoda, Tarbosaurus, palaeoecology, carnivory, predation, scavenging.

David W.E. Hone [dwe hone@ yahoo.com], Key Laboratory of Evolutionary Systematics of Vertebrates, Institute of Vertebrate Palaeontology and Palaeoanthropology, Xhizhimenwai Dajie 142, Beijing 100044, China; Mahito Watabe [moldavicum@pa2.so-net.ne.jp], Hayashibara Museum of Natural Sciences, 2-3, Shimoishii-1, Okayama 700-0907, Japan.

This is an open-access article distributed under the terms of the Creative Commons Attribution License (for details please see creativecommons.org), which permits unrestricted use, distribution, and reproduction in any medium, provided the original author and source are credited. 
